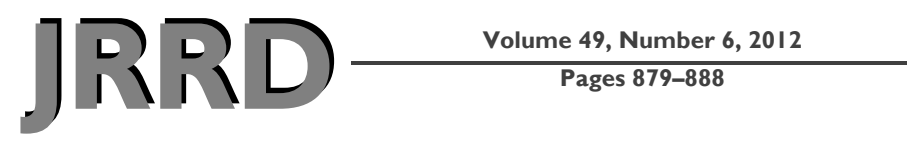

\title{
Psychometric study of the Neurobehavioral Symptom Inventory
}

\author{
Paul R. King, PhD; ${ }^{1-2^{*}}$ Kerry T. Donnelly, PhD ${ }^{3}$ James P. Donnelly, PhD ${ }^{2}$ Mina Dunnam, PhD; ${ }^{4}$ Gary Warner, \\ PhD $;^{5}$ C. J. Kittleson, PsyD; ${ }^{6}$ Charles B. Bradshaw, PhD; ${ }^{7}$ Michelle Alt, MA; ${ }^{3}$ Scott T. Meier, PhD ${ }^{2}$ \\ ${ }^{1}$ Center for Integrated Healthcare, Department of Veterans Affairs (VA) Western New York Healthcare System-Buffalo, \\ Buffalo, NY; ${ }^{2}$ Department of Counseling, School, and Educational Psychology, The University at Buffalo, State Univer- \\ sity of New York, Buffalo, NY; ${ }^{3}$ Behavioral Health Careline, VA Western New York Healthcare System-Buffalo, Buffalo, \\ NY; ${ }^{4}$ Behavioral Health Careline, Stratton VA Medical Center, Albany, NY; ${ }^{5}$ Behavioral Health Careline, Canandaigua \\ VA Medical Center, Canandaigua, NY; ${ }^{6}$ Behavioral Health Careline, Bath VA Medical Center, Bath, NY; ${ }^{7}$ Behavioral \\ Health Careline, Syracuse VA Medical Center, Syracuse, NY
}

\begin{abstract}
The Department of Veterans Affairs (VA) uses the Neurobehavioral Symptom Inventory (NSI) to measure postconcussive symptoms in its comprehensive traumatic brain injury (TBI) evaluation. This study examined the NSI's item properties, internal consistency, and external validity. Data were obtained from a federally funded study of the experiences of combat veterans. Participants included 500 Operations Iraqi and Enduring Freedom veterans, 219 of whom sustained at least one TBI. Data were collected at five VA medical centers and one VA outpatient clinic across upstate New York. Measures included neuropsychological interview, NSI, Beck Anxiety Inventory, Beck Depression Inventory-II, and Posttraumatic Stress Disorder Checklist-Military Version. The NSI demonstrated high internal consistency (total alpha $=0.95$; subscale alpha $=0.88$ to 0.92). Subscale totals based on Caplan et al.'s factor analysis correlated highly with the NSI total score $(r=$ 0.88 to 0.93 ). NSI scores differentiated veterans with TBI history from those without but were strongly influenced by variance associated with probable posttraumatic stress disorder, depression, and generalized anxiety. Results suggest that the NSI is a reliable and valid measure of postconcussive symptoms. Scale validity is evident in the differentiation of TBI and non-TBI classifications. The scale domain is not limited to TBI, however, and extends to detection of probable effects of additional affective disorders prevalent in the veteran population.
\end{abstract}

Key words: brain concussion, brain injuries, comprehensive TBI evaluation, Neurobehavioral Symptom Inventory, neuropsychology, postconcussion symptoms, posttraumatic, stress disorders, traumatic brain injury, veterans.

\section{INTRODUCTION}

Postconcussive symptoms, including affective, somatic, sensory, and cognitive complaints, commonly occur after mild traumatic brain injury (mTBI) [1-4]. However, these symptoms are not specific to mTBI. They overlap with many other disorders, such as depression, generalized anxiety disorder (GAD), and posttraumatic stress disorder (PTSD), as well as some experiences common to everyday life (e.g., headaches) [5-9]. Estimates suggest that as many as 20 percent of veterans of Operation Iraqi Freedom/Operation Enduring Freedom (OIF/OEF) have experienced at

\footnotetext{
Abbreviations: $\mathrm{BAI}=$ Beck Anxiety Inventory, BDI-2 $=$ Beck Depression Inventory-II, GAD = generalized anxiety disorder, LOC $=$ loss of consciousness, $\mathrm{mTBI}=$ mild traumatic brain injury, NSI = Neurobehavioral Symptom Inventory, OIF/OEF $=$ Operation Iraqi Freedom/Operation Enduring Freedom, PCL-M = PTSD Checklist-Military Version, PTSD = posttraumatic stress disorder, $\mathrm{R} \& \mathrm{D}=$ research and development, $\mathrm{SD}=$ standard deviation, TBI = traumatic brain injury, VA = Department of Veterans Affairs, VISN 2 = New York Veterans Integrated Services Network.

*Address all correspondence to Paul R. King, PhD; Center for Integrated Healthcare, VA Western New York Healthcare System, 3495 Bailey Ave, Buffalo, NY 14215; 716-8626038; fax: 716-862-6734. Email: Paul.King2@va.gov http://dx.doi.org/10.1682/JRRD.2011.03.0051
} 
least one traumatic brain injury (TBI) [10-12]. Approximately one-third of those veterans with TBI have comorbid PTSD or depression, and significant proportions also experienced a host of other affective concerns and physical injuries both during deployment and postdeployment [10-11]. Identification and management of postconcussive symptoms, therefore, pose a notable clinical challenge [13-14].

In 2007, the Department of Veterans Affairs (VA) mandated screening and follow-up for TBI and associated symptoms for all veterans of OIF/OEF [14-16]. A positive TBI screen is indicated by an individual veteran's endorsement of exposure to a potential TBI event, loss of consciousness (LOC) or alteration of consciousness, symptoms proximal to the injury, and current symptoms. Positive screens result in referral for a comprehensive TBI evaluation (also known as the second-level evaluation), which includes administration of the Neurobehavioral Symptom Inventory (NSI), a self-report measure of current postconcussive symptoms, as well as a medical examination and additional diagnostic testing as necessary $[15,17]$.

The current version of the NSI was first published as a symptom checklist in 1995 by Cicerone and Kalmar in the Journal of Head Trauma Rehabilitation [17]. In their study, the authors recruited 50 patients diagnosed with TBI based on criteria of altered mental status due to impact or acceleration/deceleration injury and the potential presence of LOC $(\leq 30 \mathrm{~min})$ or posttraumatic amnesia $(\leq 24 \mathrm{~h})$. Via cluster analysis, they grouped patientendorsed symptoms into four distinct categories: affective, cognitive, somatic, and sensory. Symptoms such as headaches, difficulty sleeping, numbness, difficulty hearing, and change in taste or smell did not cluster into any category and were excluded from their follow-up analyses, though they remain listed as items on the measure. A more recent study by Caplan and colleagues using data collected from three large military samples utilized factor analysis to show that a three-factor model composed of somatic/sensory, affective, and cognitive symptoms provided a better fit for symptom groupings [3].

Although the initial intent of Cicerone and Kalmar's study was to provide commentary on the structure of postconcussive symptom reporting, current clinical use of the measure is actually oriented toward a quantification of perceived symptom severity $[15,17]$. However, a recent study by Donnelly and colleagues aimed at examining potential NSI response patterns raised questions about the NSI's ability to accurately identify symptoms uniquely associated with TBI [18]. In this study, 75 vet- erans with a history of TBI completed a series of selfreport measures and a neuropsychological test battery. Those veterans with probable PTSD yielded significantly higher aggregate NSI scores than did those without. Another study by Benge et al. echoed these findings by demonstrating that the presence of PTSD accounted for substantial variance (5\%-38\%) in postconcussive symptom reporting [4].

The present study aims to build on this knowledge base and further clarify the NSI's psychometric properties in three ways: first, by providing an item analysis of the NSI; second, by determining the internal consistency of the NSI; and finally, by estimating the external validity of the NSI relative to probable TBI, PTSD, depression, and GAD.

\section{METHODS}

This investigation into the psychometric properties of the NSI is one component of a multisite, longitudinal study of the experiences of OIF/OEF veterans. Item analyses and estimates of internal consistency and external validity are provided. Expert ratings based on a structured diagnostic interview provided the criterion for TBI diagnosis in this study. Each participating site was granted approval from both its institutional review board and research and development (R\&D) committee. Participant responses are protected via a Certificate of Confidentiality granted by the National Institute of Mental Health. A complete description of our methodology can be found in a separate publication [19].

\section{Participants}

The data set for the present study comprises 500 veterans residing in the upstate New York Veterans Integrated Services Network (VISN 2). Participants were recruited from five large VA medical centers across New York State and one outpatient clinic, with representation from urban, suburban, and rural geographic regions. OIF/ OEF veterans who intended to remain in upstate New York for the 18-month duration of the parent study were eligible for inclusion, with the exception of those who lacked capacity to provide informed consent. No veterans were excluded based on the consent criterion, however, and no vulnerable participants were included.

The sample included individuals recruited from a registry of OIF/OEF veterans across VISN $2(n=248)$, as well 
as veterans referred for clinical neuropsychological or polytrauma assessment $(n=252)$. Participants were compensated for their time and travel. Most veterans completed the full interview and test battery, although a small number ( $n=$ 6) discontinued because of adverse reactions or time constraints. Participants included 452 (90.4\%) male and 48 (9.6\%) female veterans ranging in age from 20 to 60 (mean \pm standard deviation $[\mathrm{SD}]=32.2 \pm 8.9$ ). Their number of years of service ranged from 1 to 33 (mean \pm SD $=10.0 \pm$ 7.5), and they reported a range of 1 to as many as 15 combat deployments (mean $\pm \mathrm{SD}=1.7 \pm 1.2$ ). Table 1 briefly summarizes additional participant characteristics.

\section{Measures}

\section{Clinical Interview}

A structured diagnostic interview was cooperatively developed and administered by study investigators to gauge the likelihood and severity of TBI among participants. The interview referenced diagnostic criteria outlined by The Management of Concussion/mTBI Working Group [20] and are available in the Appendix (available online only). Additional items were added to further detail circumstances, events, and symptoms surrounding the injury. The interview did not assess for current postconcussive symptoms because this was not required for a diagnosis of TBI. That information is elicited in the VA TBI Screening Tool, which we have described elsewhere [19].

Table 2 summarizes additional details gleaned from the interview, including the frequency and severity of identified head injuries.

\section{Neurobehavioral Symptom Inventory}

The NSI is a 22-item self-report measure of postconcussive symptoms [17]. On this measure, respondents rate the degree of symptom severity on a five-point scale that ranges from zero (none; symptom is rarely ever present/not a problem at all) to four (very severe; symptom is almost always present/impairs performance at work, school, or home/individual probably cannot function without help). A full listing of symptoms assessed in the NSI can be found in Table 3, organized based on Caplan et al.’s suggested symptom groupings [3].

\section{Beck Anxiety Inventory}

The Beck Anxiety Inventory (BAI) is a 21-item measure of GAD symptoms [21]. Symptoms are rated on a 4-point scale (0 to 3 ) of how intensely they have been
Table 1.

Participant demographics.

\begin{tabular}{|c|c|}
\hline Demographic & $\begin{array}{c}\text { Value, \% or } \\
\text { Mean (Range) }\end{array}$ \\
\hline \multicolumn{2}{|l|}{ Highest Education } \\
\hline Some High School & 2.2 \\
\hline High School Diploma & 24.6 \\
\hline Some College & 41.6 \\
\hline 2-Year Degree & 16.4 \\
\hline 4-Year Degree & 9.6 \\
\hline Some Graduate School & 2.0 \\
\hline Graduate Degree & 3.6 \\
\hline \multicolumn{2}{|l|}{ Race/Ethnicity } \\
\hline African American & 5.4 \\
\hline Asian American & 1.0 \\
\hline Caucasian & 85.8 \\
\hline Hispanic & 4.2 \\
\hline Native American & 1.0 \\
\hline Other & 2.6 \\
\hline Missing & $<1.0$ \\
\hline \multicolumn{2}{|l|}{ Vocational Status } \\
\hline Full-Time Work & 50.0 \\
\hline Part-Time Work & 8.6 \\
\hline Full-Time Student & 14.8 \\
\hline Part-Time Student & 1.2 \\
\hline Volunteer & 0.6 \\
\hline Unemployed/Disabled & 24.8 \\
\hline \multicolumn{2}{|l|}{ Relationship Status } \\
\hline Divorced & 15.8 \\
\hline Married & 49.4 \\
\hline Single & 34.4 \\
\hline Widowed & 0.4 \\
\hline \multicolumn{2}{|l|}{ Sex } \\
\hline Male & 90.4 \\
\hline Female & 9.6 \\
\hline \multicolumn{2}{|l|}{ Affective Symptoms } \\
\hline Probable PTSD (PCL-M ㄴ50) & 47.2 \\
\hline Probable GAD (BAI $\geq 16)$ & 42.6 \\
\hline Probable Depression (BDI-2 $\geq 20$ ) & 46.9 \\
\hline \multicolumn{2}{|l|}{ Other } \\
\hline Years in Military & $10.0(1-33)$ \\
\hline No. Deployments to War Zone & $1.6(1-15)$ \\
\hline $\begin{array}{l}\text { Months since Return from Most Recent } \\
\text { Deployment }\end{array}$ & $36.1(1-108)$ \\
\hline Service-Connected for Any Disability & 55.4 \\
\hline Self-Reported Blast Exposure & 84.2 \\
\hline Proximity to Blast (ft) & $285.5(0-2,500)$ \\
\hline $\begin{array}{l}\text { BAI = Beck Anxiety Inventory, BDI-2 = Beck D } \\
\text { generalized anxiety disorder, PCL-M = PTSI } \\
\text { PTSD = posttraumatic stress disorder. }\end{array}$ & $\begin{array}{l}\text { Inventory-II, GAD } \\
\text { st-Military Versic }\end{array}$ \\
\hline
\end{tabular}


experienced over a 1-week period. Queried symptoms include somatic and emotional indicators of anxiety, such as increased heartbeat, indigestion, difficulty breathing, and various fears.

\section{Beck Depression Inventory-II}

The Beck Depression Inventory-II (BDI-2) is a 21-item measure of subjective depressive symptoms [22]. Symptoms are rated on a 4-point scale (0 to 3) of how intensely they have been experienced over a 2-week period. Queried symptoms include suicidal thinking behaviors, crying, and other positive and vegetative symptoms of depression, such as changes in sleep and appetite.

\section{PTSD Checklist-Military Version}

The PTSD Checklist-Military Version (PCL-M) is a 17-item self-report survey of PTSD symptoms based on Diagnostic and Statistical Manual of Mental DisordersFourth Revision diagnostic criteria [23]. Respondents are

Table 2.

Severity, temporal proximity, and frequency of participants' traumatic brain injuries (TBIs).

\begin{tabular}{lc}
\hline \multicolumn{1}{c}{ Severity Level/Description } & $\begin{array}{c}\text { Value, } \boldsymbol{n}(\mathbf{\%}) \\
\text { or Mean } \\
\text { (Range) }\end{array}$ \\
\hline No TBI & $281(56.2)$ \\
Clinician-Confirmed TBI & $219(43.8)$ \\
Transient Confusion, No LOC, MSA <15 min & $68(13.6)$ \\
Transient Confusion, No LOC, MSA 15 min-1 h & $10(2.0)$ \\
Transient Confusion, No LOC, MSA 1-24 h & $15(3.0)$ \\
Transient Confusion, No LOC, MSA >24 h & $11(2.2)$ \\
LOC (s to several min), MSA <15 min & $45(9.0)$ \\
LOC (s to several min), MSA >15 min & $63(12.6)$ \\
LOC 1-24 h & $6(1.2)$ \\
LOC $>24$ h & $1(0.2)$ \\
Months since Most Recent TBI & $41.45(0-96)$ \\
No. TBIs & \\
0 & $281(56.2)$ \\
1 & $168(33.6)$ \\
2 & $36(7.2)$ \\
3 & $8(1.6)$ \\
7 & $4(0.8)$ \\
\hline LOC $=$ loss of consciousness, MSA = mental status abnormalities. \\
\hline
\end{tabular}

asked to rate the frequency of PTSD-related symptoms on a 5-point scale from 1 (not at all) to 5 (extremely) over the course of a 1-month period. Items probe such experiences as disturbing memories and dreams, relational or interpersonal difficulties, and other somatic and cognitive concerns.

\section{Procedure}

Data were derived from the parent study. Complete details on recruitment, sampling, consent, and interview procedures can be found in our previous work [19].

Items in the structured interview were extensively reviewed for consensus on administration and scoring among the investigators before implementation, with ongoing biweekly consultation once data collection commenced. Interviews were conducted by licensed psychologists, and the NSI, BDI-2, BAI, and PCL-M were then administered by trained research assistants who were supervised by the licensed psychologist investigators at

Table 3.

Neurobehavioral Symptom Inventory factors organized by Caplan et al.’s suggested symptom groupings [3].

\begin{tabular}{lc}
\hline \multicolumn{1}{c}{ Factor } & \multicolumn{1}{c}{$\begin{array}{c}\text { Caplan } \\
\text { Subscale }\end{array}$} \\
\hline 1. Feeling Dizzy & Somatic/Sensory \\
2. Loss of Balance & Somatic/Sensory \\
3. Poor Coordination, Clumsy & Somatic/Sensory \\
5. Nausea & Somatic/Sensory \\
6. Vision Problems, Blurring, Trouble Seeing & Somatic/Sensory \\
7. Sensitivity to Light & Somatic/Sensory \\
8. Hearing Difficulty & Somatic/Sensory \\
9. Sensitivity to Noise & Somatic/Sensory \\
10. Numbness & Somatic/Sensory \\
11. Change in Taste/Smell & Somatic/Sensory \\
12. Loss of Appetite or Increased Appetite & Somatic/Sensory \\
4. Headaches & Affective \\
17. Fatigue, Loss of Energy & Affective \\
18. Difficulty Falling or Staying Asleep & Affective \\
19. Feeling Anxious or Tense & Affective \\
20. Feeling Depressed or Sad & Affective \\
21. Irritability, Easily Annoyed & Affective \\
22. Poor Frustration Tolerance & Affective \\
13. Poor Concentration & Cognitive \\
14. Forgetfulness, Can’t Remember Things & Cognitive \\
15. Difficulty Making Decisions & Cognitive \\
16. Slowed Thinking & Cognitive \\
\hline \hline
\end{tabular}


their respective study sites. All data included in the study were collected prospectively. No information from medical records was included in these analyses. Participants were compensated $\$ 75$ for their time.

\section{Analysis}

\section{Data Screening and Quality Control}

Before data analysis, cases were reviewed for accuracy across multiple stages. The data set was first carefully checked for accuracy by study staff, and all items were examined again before analysis to be certain that the values were within range. Incomplete data resulted in the exclusion of NSI values from 6 cases, BDI-2 data from 11 cases, and BAI and PCL-M data from 12 cases. Demographic characteristics and descriptive statistics are reported for relevant test items and measures.

\section{Computation of Total and Subscale Scores}

Although Cicerone and Kalmar initially did not report a total NSI score, the sum of all 22 symptom ratings was calculated for the purposes of this study [17]. Beyond the NSI total score, we computed the sum totals for each factor suggested in Caplan et al.'s study, which resulted in three additional subscales (somatic/sensory, affective, and cognitive) [3].

\section{Analysis of Primary Research Questions}

All analyses were performed with PASW version 17 or IBM SPSS version 19 (IBM; Armonk, New York). Internal consistency reliability of the NSI was examined via Holmbeck and Devine's suggestion and included a calculation of coefficient alpha for the NSI total and three subscales [24]. Independent samples $t$-tests explored differences in NSI and affective scores between participants with TBI history versus those without based on the structured diagnostic interview. Pearson correlation coefficients and partial correlations were used to determine item-total correlations as well as to estimate the strength and unique variance in the relationships between the NSI total score and TBI and affective diagnostic groups. PCLM scores of 50 or above, BDI-2 scores of 20 (moderate depression) or above, and BAI scores of 16 (moderate anxiety) or above were used to determine probable positive diagnostic groups.

\section{RESULTS}

\section{Sample Descriptive Statistics}

The sample was primarily Caucasian (85.8\%) but was similar to general OIF/OEF sex division [25]. For those participants who were confirmed to have sustained a TBI, mean time since injury was more than 3 years (mean \pm $\mathrm{SD}=41.45 \pm 21.66 \mathrm{mo}$; range $=0-96 \mathrm{mo}$ ). Among individual NSI items, the most highly endorsed symptoms included irritability, sleep disturbance, anxiety, and forgetfulness. A summary of descriptive statistics for the combined sample and subsamples of previously braininjured patients $(\mathrm{TBI}+)$ and non-brain-injured controls (TBI-) can be found in Table 4.

\section{Item and Scale Analysis by Traumatic Brain Injury Status}

Item-total correlations yielded relatively high degrees of correspondence among items such as anxiety $(r=0.83)$, forgetfulness ( $r=0.81$ ), and concentration and poor frustration tolerance ( $r=0.80$ for each). Caplan et al.'s affective and somatic/sensory subscales correlated most highly with the NSI total score ( $r=0.93$ and 0.92 , respectively). Relatively lower degrees of correspondence existed between the NSI total score and changes in taste or smell $(r=0.49)$, nausea ( $r=0.56)$, and hearing difficulty $(r=0.57)$. Results of multiple independent samples $t$-tests indicated statistically significant differences between the patient sample (TBI+) and control group (TBI-) on all NSI and affective variables ( $p<0.01$ for each). Calculation of Cohen $d$ and respective confidence intervals suggested relatively high magnitudes of difference (roughly 0.44 to 0.85 ) for virtually all NSI and affective observations. Somatic/sensory reports showed the greatest between-group difference in postconcussive symptom reporting $(d=0.82)$, but the largest magnitude of effect was noted between patient and control reports of PTSD symptoms $(d=0.85)$. A summary of these data can be found in Table 4 .

\section{Reliability}

\section{Internal Consistency}

A total of 494 observations of each of the 22 NSI items and three subscales was used in the calculation of internal consistency (Table 5). Cronbach alpha for the comprehensive scale was 0.95 , which indicates a high degree of internal consistency. High alphas for each of the subscales were observed as well (0.88 to 0.92$)$. 
Table 4.

Item-Neurobehavioral Symptom Inventory (NSI) total correlations and independent samples $t$-tests between groups of subjects with TBI (TBI+) and without TBI (TBI-).

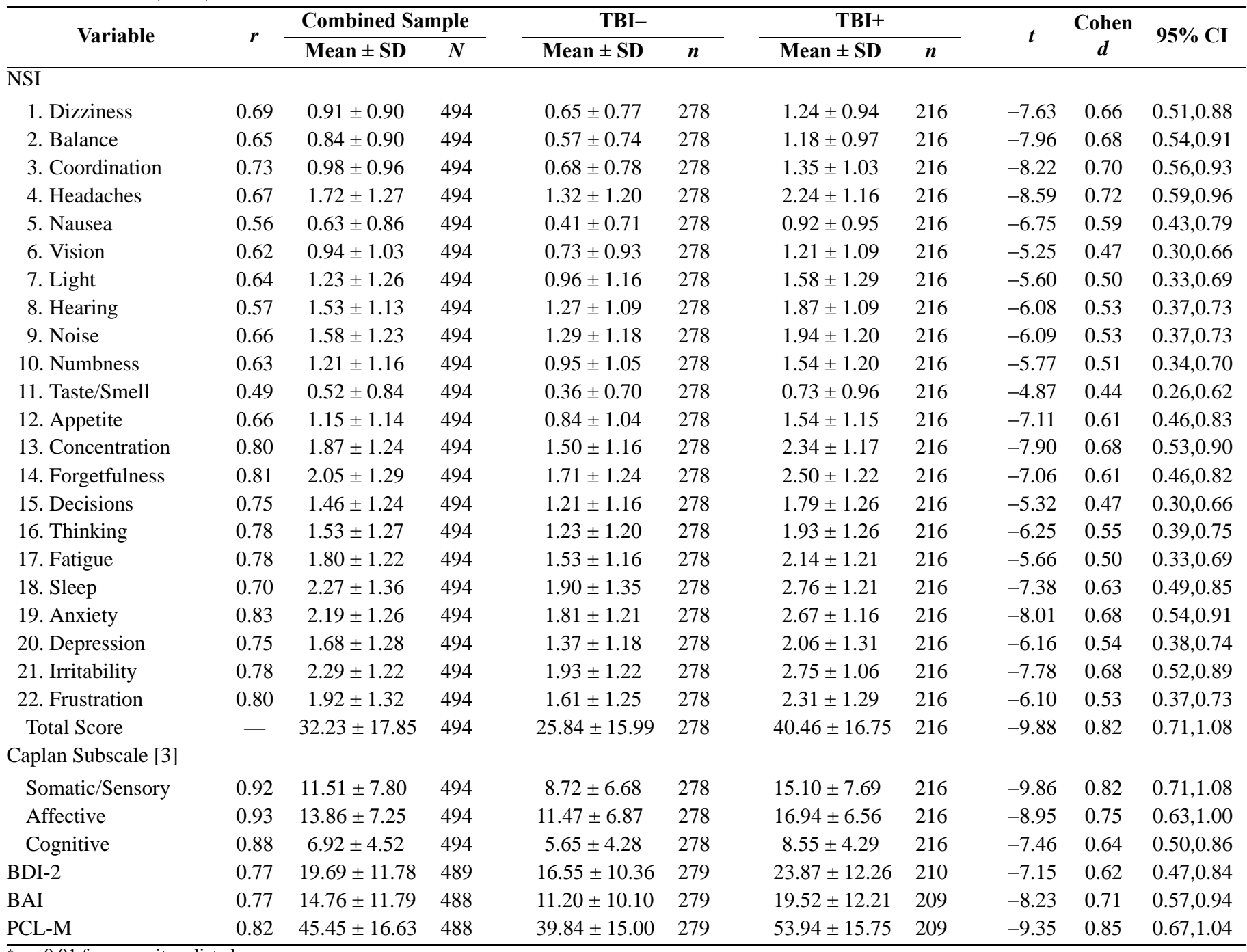

${ }^{*} p<0.01$ for every item listed.

BAI = Beck Anxiety Inventory, BDI-2 = Beck Depression Inventory-II, CI = confidence interval, PCL-M = PTSD Checklist-Military Version, SD = standard deviation, TBI = traumatic brain injury.

\section{External Validity}

Correlations and partial correlations were examined to estimate the strength and unique variance in the relationships between the NSI total score and probable diagnoses of TBI, PTSD (PCL-M score $\geq 50$ ), depression (BDI-2 score $\geq 20$ ) and GAD (BAI score $\geq 16$ ). These coefficients were first calculated for the complete sample and then by sequentially estimating the partial correlation controlling for the other three variables.

The correlations in Table 6 show a moderate relationship of NSI total with TBI status. In contrast, consis- tent and moderately strong positive relationships between the NSI total and all three affective measures were evidenced. The partial correlations provide estimates of the unique variance shared by the NSI with probable TBI, PTSD, depression, and GAD. This pattern of coefficients suggests that NSI scores were more strongly related to affective measures than to probable TBI.

The final analysis addressed the pattern of NSI total scores across all possible combinations of the probable diagnostic groups. There are a total of 16 possibilities, ranging from not meeting criteria for any probable diagnostic 
Table 5.

Internal consistency estimates for Neurobehavioral Symptom Inventory (NSI).

\begin{tabular}{lccc}
\hline \multicolumn{1}{c}{ Scale } & No. Items & $\boldsymbol{n}$ & $\begin{array}{c}\text { Cronbach } \\
\text { Alpha }\end{array}$ \\
\hline NSI Total & 22 & 494 & 0.95 \\
Caplan Subscale [3] & & & \\
$\quad$ Somatic/Sensory & 11 & 494 & 0.88 \\
Affective & 7 & 494 & 0.91 \\
Cognitive & 4 & 494 & 0.92 \\
\hline \hline
\end{tabular}

group to meeting criteria for all four concurrently. The scores were plotted by group and arranged in ascending order of the mean values as shown in the Figure. In addition to the NSI mean and 95 percent confidence interval, the Figure also gives the number and percentage of participants in each of the groups. The most prevalent group is that which met none of the four probable diagnostic group criteria (148 veterans; $29.9 \%$ of the study sample). This group represents the lowest mean NSI. At the opposite end of the NSI score continuum is the second most prevalent group, which met all four probable diagnostic group criteria (92 veterans; $18.6 \%$ of the sample). The overall pattern suggests that the NSI is sensitive to increasing diagnostic burden in a roughly additive way. That is, the NSI total scores tend to increase as additional diagnostic thresholds are crossed.

\section{DISCUSSION}

A significant proportion of modern combat veterans experience TBI, and a substantial body of literature indicates that many of these veterans report "postconcussive symptoms." However, a comparable series of studies also substantiate that physical, emotional, and cognitive complaints commonly associated with postconcussive symptoms, such as headache, sensitivity to light and sound, memory problems, anxiety, and depression, are nonspecific, thereby overlapping with many other disorders. Especially germane with this population is the known overlap of such symptoms with PTSD. Accordingly, accurate and timely identification and management of these symptoms are notably and persistently challenging.

In this study, we aimed to detail the psychometrics of the NSI, the symptom complaint measure that VA uses to evaluate veterans' reports of postconcussive symptoms. Specifically, we provided an item analysis of the NSI, demonstrated its internal consistency, and estimated its external
Table 6.

Biserial correlations and partial correlations of Neurobehavioral Symptom Inventory (NSI) with probable traumatic brain injury (TBI), posttraumatic stress disorder (PTSD), depression, and anxiety.

\begin{tabular}{lcc}
\hline \multicolumn{1}{c}{ Variable } & $\begin{array}{c}\text { Correlation } \\
(\boldsymbol{n}=\mathbf{4 9 4})\end{array}$ & $\begin{array}{c}\text { Partial Correlation* } \\
(\boldsymbol{n}=\mathbf{4 8 8})\end{array}$ \\
\hline NSI-TBI & 0.41 & 0.24 \\
NSI-PCL-M & 0.67 & 0.33 \\
NSI-BDI-2 & 0.64 & 0.30 \\
NSI-BAI & 0.65 & 0.33 \\
\hline N
\end{tabular}

Note: All coefficients significant at $p<0.001$.

${ }^{*}$ Calculated controlling for other three variables (e.g., partial correlation of NSI and TBI, controlling for probable PTSD, BDI-2, and BAI).

BAI = Beck Anxiety Inventory, BDI-2 = Beck Depression Inventory-II, PCL$\mathrm{M}=$ PTSD Checklist-Military Version.

validity relative to probable TBI, PTSD, depression, and GAD. Ultimately, our results showed a high degree of correspondence among most NSI items and the NSI total score, particularly anxiety, forgetfulness, difficulty concentrating, and poor frustration tolerance ( $r=0.80$ to 0.83 ), and the overall scale demonstrated a high degree of internal consistency $(\alpha=0.95)$. Also, subscale totals based on Caplan et al.'s somatic/sensory, affective, and cognitive symptom groupings correlated highly with the NSI total score ( $r=0.88$ to 0.93 ) and each subscale demonstrated high internal consistency as well ( $\alpha=0.88$ to 0.92 ).

As expected, the veterans who had experienced TBI rated all NSI symptoms significantly higher than controls. However, they also reported significantly higher symptom endorsements of GAD, depression, and PTSD symptoms as measured by the BAI, BDI-2, and PCL-M, suggesting higher overall levels of affective disturbance in this group as well. As evidenced by our investigation of external validity, NSI total scores correlated strongly with all affective measures, regardless of TBI status. The strongest overall correlation was observed between the NSI and PCL-M, but the magnitude of this correlation was similar to those for depression and GAD. Partial correlations estimated the amount of unique variance shared among the NSI, TBI, and affective scores, and affective ratings again emerged as the strongest source of variance. When the pattern of NSI scores in relation to probable diagnoses of TBI, PTSD, depression, and anxiety were examined, total symptoms clearly increased in an approximately linear and additive fashion.

Several limitations are evident in our study and warrant mention. Perhaps most noteworthy is the fact that the majority of the previously brain-injured veterans in our 


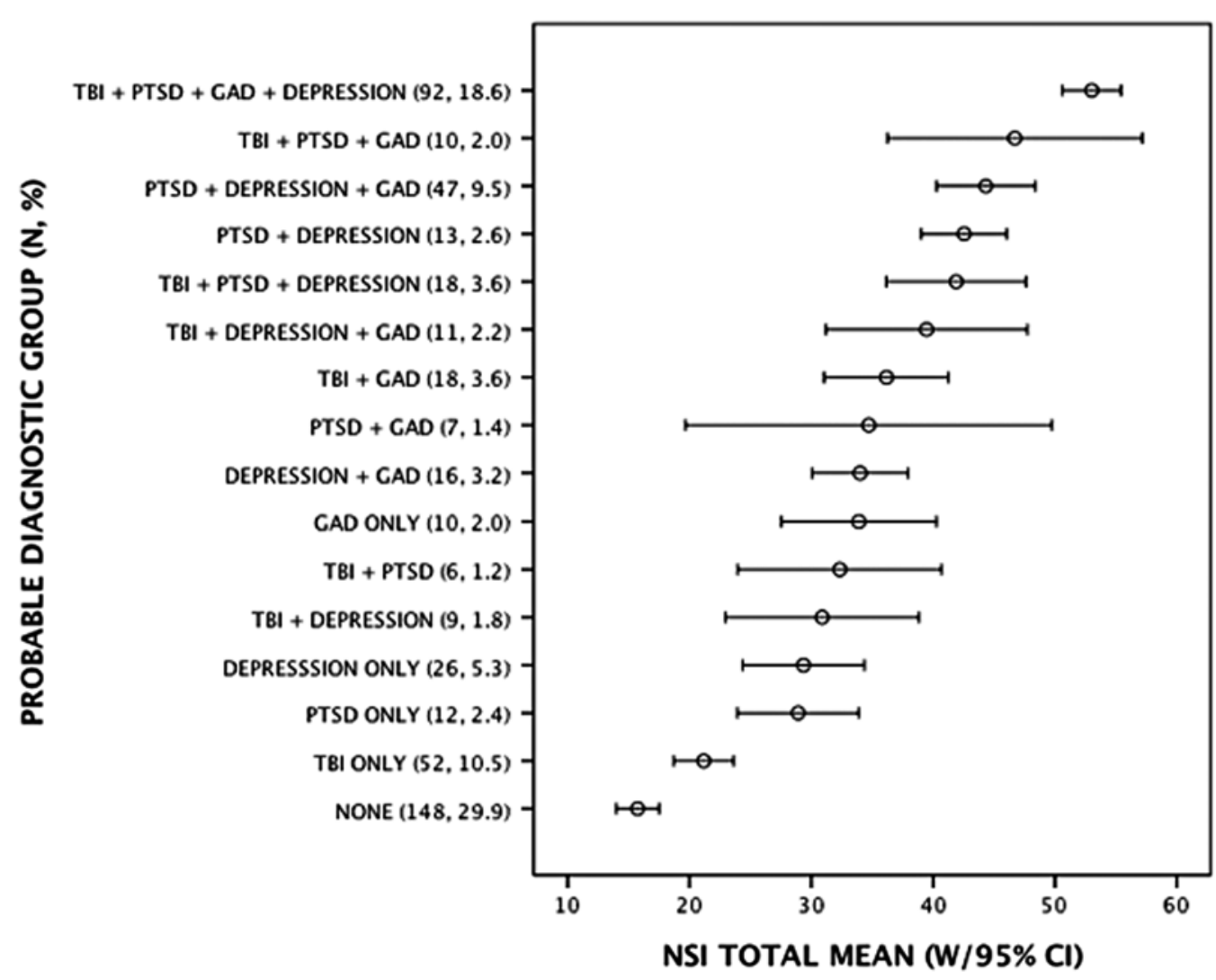

Figure.

Neurobehavioral Symptom Inventory (NSI) total scores (mean and 95\% confidence interval [CI]) by probable diagnostic groups ( $n$, \% of sample). Line center points reflect NSI mean for each probable diagnostic group; line width represents $95 \% \mathrm{Cl}$. GAD = generalized anxiety disorder, PTSD = posttraumatic stress disorder, $\mathrm{TBI}$ = traumatic brain injury.

sample were injured on average more than 3 years before completing our measures. Therefore, these results may not apply to other civilian or even Active Duty samples that may report on symptom complaints more proximal to the date of injury. Although the TBI+ group reported significantly higher affective symptoms than controls, we are only able to report the presence of these symptoms, not to discern whether these ratings stem from the TBI-inducing incident, were exacerbated by it, predate it, or are completely independent of it altogether. Also, as a group, even noninjured controls reported generally high endorsements of PTSD symptoms based on PCL-M scores (mean \pm SD = $45.5 \pm 16.6$ ) and moderate levels of depression per BDI-2 scores (mean $\pm \mathrm{SD}=19.7 \pm 11.8$ ); therefore, our results may not accurately portray the magnitude of difference in symptom reports that might be found in a less traumatized, less depressed, or civilian control sample, in which rates of PTSD are significantly lower [26]. Furthermore, we did not have access to individually coded PCL-M items and, therefore, could not address same-item endorsement on the NSI (e.g., irritability, sleep disturbance, difficulty concentrating), which likely skewed the strength of the observed relationships. Finally, because our structured interview did not assess the presence of current postconcussive symptoms in the patient sample, we were unable to use this as a metric for comparison with the control sample.

Despite these limitations, our findings indicate that probable PTSD and other affective concerns are a significant factor in reports of postconcussive symptoms in veterans with a documented history of TBI. Future research may investigate the effect of medical, psychological, and psychiatric interventions on mitigating symptoms in this unique population as well as the potential benefits of targeting specific affective presentations (e.g., hyperarousal symptoms in PTSD) known to overlap with postconcussive symptom complaints. 


\section{CONCLUSIONS}

In summary, the NSI appears to be a reliable and valid measure of postconcussive symptoms. However, consistent with previous research, we have demonstrated that significant affective disturbance has the potential-if not likelihood-to inflate ratings of postconcussive symptoms in noninjured controls and veterans with a history of TBI even many years after injury, long after we might expect true "postconcussive" symptoms to have resolved.

\section{ACKNOWLEDGMENTS}

Author Contributions:

Study design: P. R. King, K. T. Donnelly, J. P. Donnelly, M. Dunnam, G. Warner, C. J. Kittleson, C. B. Bradshaw, M. Alt, S. T. Meier. Data analysis and interpretation: J. P. Donnelly, P. R. King, K. T. Donnelly.

Drafting of manuscript: P. R. King, K. T. Donnelly, J. P. Donnelly. Critical revision and approval of manuscript: P. R. King, K. T. Donnelly, J. P. Donnelly, M. Dunnam, G. Warner, C. J. Kittleson, C. B. Bradshaw, M. Alt, S. T. Meier.

Financial Disclosures: The authors have declared that no competing interests exist.

Funding/Support: This material was based on work supported in part by the VA, Veterans Health Administration, Office of R\&D, Health Sciences R\&D (Service Directed Research grant 06-162). Writing of this manuscript was supported in part by the Office of Academic Affiliations, Advanced Fellowship Program in Mental Illness Research and Treatment, VA.

Additional Contributions: The authors would like to acknowledge Sarah Piwowarczyk, Nicole Mattila, Chad Lindstrom, Kirk Jackson, Jonathan Riven, Kerry Grohman, Megan Holcomb, Wendy Guyker, Emily Pikoff-Mirwis, Sarah Newman, and Melissa Choi for their assistance in data collection and review of the manuscript.

Institutional Review: Each participating study site was granted approval from both its institutional review board and R\&D Committee. All participants consented to their involvement, and their responses are protected via a Certificate of Confidentiality granted by the National Institute of Mental Health.

Participant Follow-Up: The authors do not plan to inform participants of the publication of this study.

Disclaimer: The views expressed in this article are those of the authors and do not necessarily reflect the position or policy of the VA or the U.S. Government.

\section{REFERENCES}

1. Brenner LA, Ivins BJ, Schwab K, Warden D, Nelson LA, Jaffee M, Terrio H. Traumatic brain injury, posttraumatic stress disorder, and postconcussive symptom reporting among troops returning from Iraq. J Head Trauma Rehabil.
2010;25(5):307-12. [PMID:20042982]

http://dx.doi.org/10.1097/HTR.0b013e3181cada03

2. Sullivan K, Garden N. A comparison of the psychometric properties of 4 postconcussion syndrome measures in a nonclinical sample. J Head Trauma Rehabil. 2011;26(2): 170-76. [PMID:20535029] http://dx.doi.org/10.1097/HTR.0b013e3181e47f95

3. Caplan LJ, Ivins B, Poole JH, Vanderploeg RD, Jaffee MS, Schwab K. The structure of postconcussive symptoms in 3 US military samples. J Head Trauma Rehabil. 2010;25(6): 447-58. http://dx.doi.org/10.1097/HTR.0b013e3181d5bdbd

4. Benge JF, Pastorek NJ, Thornton GM. Postconcussive symptoms in OEF-OIF veterans: factor structure and impact of posttraumatic stress. Rehabil Psychol. 2009; 54(3):270-78. [PMID:19702425] http://dx.doi.org/10.1037/a0016736

5. Carlson KF, Kehle SM, Meis LA, Greer N, Macdonald R, Rutks I, Sayer NA, Dobscha SK, Wilt TJ. Prevalence, assessment, and treatment of mild traumatic brain injury and posttraumatic stress disorder: a systematic review of the evidence. J Head Trauma Rehabil. 2011;26(2):103-15. [PMID:20631631] http://dx.doi.org/10.1097/HTR.0b013e3181e50ef1

6. Carlson K, Kehle S, Meis L, Greer N, MacDonald R, Wilt $\mathrm{T}$. The assessment and treatment of individuals with history of traumatic brain injury and post-traumatic stress disorder: a systematic review of the evidence. Minneapolis (MN): Department of Veterans Affairs Health Services Research and Development Service; 2009.

7. Lange RT, Iverson GL, Rose A. Depression strongly influences postconcussion symptom reporting following mild traumatic brain injury. J Head Trauma Rehabil. 2011; 26(2):127-37. [PMID:20631632] http://dx.doi.org/10.1097/HTR.0b013e3181e4622a

8. Kennedy JE, Jaffee MS, Leskin GA, Stokes JW, Leal FO, Fitzpatrick PJ. Posttraumatic stress disorder and posttraumatic stress disorder-like symptoms and mild traumatic brain injury. J Rehabil Res Dev. 2007;44(7):895-920. [PMID:18075948] http://dx.doi.org/10.1682/JRRD.2006.12.0166

9. Lew HL, Vanderploeg RD, Moore DF, Schwab K, Friedman L, Yesavage J, Keane TM, Warden DL, Sigford BJ. Overlap of mild TBI and mental health conditions in returning OIF/OEF service members and veterans. J Rehabil Res Dev. 2008;45(3):xi-xvi. [PMID:18629743]

10. Hoge CW, McGurk D, Thomas JL, Cox AL, Engel CC, Castro CA. Mild traumatic brain injury in U.S. Soldiers returning from Iraq. N Engl J Med. 2008;358(5):453-63. [PMID:18234750] http://dx.doi.org/10.1056/NEJMoa072972

11. Tanielian T, Jaycox LH, editors. Invisible wounds of war: psychological and cognitive injuries, their consequences, 
and services to assist recovery. Santa Monica (CA): The RAND Corporation; 2008.

12. Okie S. Traumatic brain injury in the war zone. N Engl J Med. 2005;352(20):2043-47. [PMID:15901856] http://dx.doi.org/10.1056/NEJMp058102

13. Iverson GL. Clinical and methodological challenges with assessing mild traumatic brain injury in the military. J Head Trauma Rehabil. 2010;25(5):313-19. [PMID:20220528]

14. Government Accountability Office. VA health care: mild traumatic brain injury screening and evaluation implemented for OEF/OIF veterans, but challenges remain. Washington (DC): Government Accounting Office; 2008.

15. Department of Veterans Affairs. Screening and evaluation of possible traumatic brain injury in Operation Enduring Freedom (OEF) and Operation Iraqi Freedom (OIF) veterans. Washington (DC): Department of Veterans Affairs, Veterans Health Administration; 2007.

16. National Center for PTSD and Walter Reed Army Medical Center. Iraq war clinician guide. 2nd ed. Boston (MA): National Center for PTSD; 2004.

17. Cicerone KD, Kalmar K. Persistent postconcussion syndrome: the structure of subjective complaints after mTBI. J Head Trauma Rehabil. 1995;10:1-17. http://dx.doi.org/10.1097/00001199-199510030-00002

18. Donnelly K, Alt M, Donnelly J. Relationship of Neurobehavioral Symptom Inventory (NSI) responses to cognitive and affective symptoms in OEF/OIF veterans who screen positive for TBI. Poster presented at the VA QUERI National Meeting; 2008 Dec; Phoenix, AZ.

19. Donnelly KT, Donnelly JP, Dunnam M, Warner GC, Kittleson CJ, Constance JE, Bradshaw CB, Alt M. Reliability, sensitivity, and specificity of the VA traumatic brain injury screening tool. J Head Trauma Rehabil. 2011;26(6):439-53. [PMID:21386716] http://dx.doi.org/10.1097/HTR.0b013e3182005de3

20. The Management of Concussion/mTBI Working Group. VA/DOD Clinical Practice Guideline for management of concussion/mild traumatic brain injury (mTBI). Washington (DC): Department of Veterans Affairs and Department of Defense; 2009.
21. Beck AT, Steer RA. Manual for the Beck Anxiety Inventory. San Antonio (TX): Psychological Corporation; 1993.

22. Beck AT, Steer RA, Brown GK. Manual for the Beck Depression Inventory-II. San Antonio (TX): Psychological Corporation; 1996.

23. Weathers FW, Litz BT, Herman DS, Huska JA, Keane TM. The PTSD Checklist (PCL): reliability, validity, and diagnostic utility. 9th Annual Conference of the ISTSS; 1993; San Antonio, TX.

24. Holmbeck GN, Devine KA. Editorial: an author's checklist for measure development and validation manuscripts. J Pediatr Psychol. 2009;34(7):691-96. [PMID:19487232] http://dx.doi.org/10.1093/jpepsy/jsp046

25. Rutherford G, Allegria M. The Committee on the Initial Assessment of Readjustment Needs of Military Personnel, and Their Families. Returning home from Iraq and Afghanistan: preliminary assessment of readjustment needs of veterans, service members, and their families. Washington (DC): Institute of Medicine, The National Academies Press; 2010.

26. Hoge CW, Castro CA, Messer SC, McGurk D, Cotting DI, Koffman RL. Combat duty in Iraq and Afghanistan, mental health problems, and barriers to care. N Engl J Med. 2004; 351(1):13-22. [PMID:15229303] http://dx.doi.org/10.1056/NEJMoa040603

Submitted for publication March 18, 2011. Accepted in revised form November 29, 2011.

This article and any supplementary material should be cited as follows:

King PR, Donnelly KT, Donnelly JP, Dunnam M, Warner G, Kittleson CJ, Bradshaw CB, Alt M, Meier ST. Psychometric study of the Neurobehavioral Symptom Inventory. J Rehabil Res Dev. 2012;49(6):879-88.

http://dx.doi.org/10.1682/JRRD.2011.03.0051

ResearcherID: Paul R. King, PhD: G-9819-2011

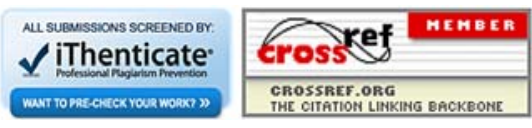

